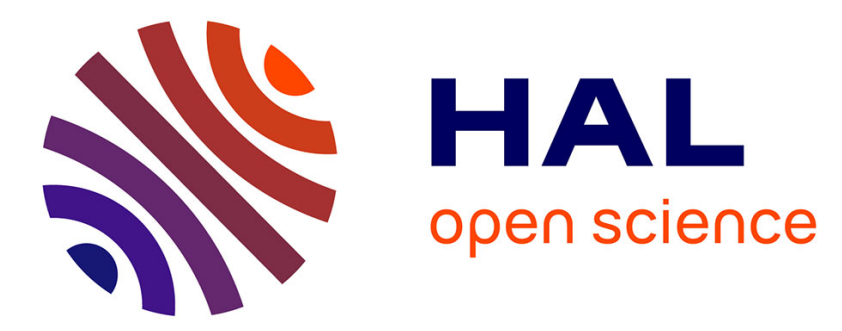

\title{
Lipid dynamics in early life stages of the icefish Chionodraco hamatus in the Dumont d'Urville Sea (East Antarctica)
}

Carolina Giraldo, Marc Boutoute, Patrick Mayzaud, an Vo Quang, Philippe Koubbi, Eric Tavernier

\section{To cite this version:}

Carolina Giraldo, Marc Boutoute, Patrick Mayzaud, an Vo Quang, Philippe Koubbi, et al.. Lipid dynamics in early life stages of the icefish Chionodraco hamatus in the Dumont d'Urville Sea (East Antarctica). Polar Biology, 2017, 40 (2), pp.313-320. 10.1007/s00300-016-1956-4 . hal-01317616

\section{HAL Id: hal-01317616 https://hal.sorbonne-universite.fr/hal-01317616}

Submitted on 18 May 2016

HAL is a multi-disciplinary open access archive for the deposit and dissemination of scientific research documents, whether they are published or not. The documents may come from teaching and research institutions in France or abroad, or from public or private research centers.
L'archive ouverte pluridisciplinaire HAL, est destinée au dépôt et à la diffusion de documents scientifiques de niveau recherche, publiés ou non, émanant des établissements d'enseignement et de recherche français ou étrangers, des laboratoires publics ou privés. 


\section{Lipid dynamics in early life stages of the icefish Chionodraco hamatus in the Dumont d'Urville Sea (East-Antarctica)}

Carolina Giraldo ${ }^{1,2 *}$, Marc Boutoute ${ }^{2}$, Patrick Mayzaud ${ }^{1,2}$ Eric Tavernier $^{3,4}$, An Vo Quang ${ }^{1,2}$, and Philippe Koubbi ${ }^{5}$

${ }^{1}$ UPMC Université Paris 06, UMR 7093, Laboratoire d'Océanographie de Villefranche, BP28, 06234 Villefranche-sur-Mer, France.

${ }^{2}$ CNRS, UMR 7093, LOV, BP 28, 06234 Villefranche-sur-Mer, France.

${ }^{3}$ Université Lille Nord de France, F-59000 Lille, France.

${ }^{4}$ ULCO, LOG, 32 avenue Foch, F-62930 Wimereux, France.

${ }^{5}$ Unité Biologie des organismes et écosystèmes aquatiques (BOREA, UMR 7208), Sorbonne Universités, Muséum national d'Histoire naturelle, Université Pierre et Marie Curie, Université de Caen Basse-Normandie, CNRS, IRD; CP26, 57 rue Cuvier 75005 Paris, France.

*Corresponding author: carolina.giraldo@univ-lille1.fr

\section{Abstract}

Lipids play a crucial role in polar regions and are of particular importance in early life stages of Antarctic fish. This work presents the significance of lipids and fatty acids (FA) in the early life stages of the icefish Chionodraco hamatus. Analysis of lipid classes (Polar lipids, LP; Cholesterol, Chol; and Triacyglycerol, TAG) suggested different energy allocation strategies in preflexion $(<25 \mathrm{~mm})$ and postflexion larvae $(>25 \mathrm{~mm})$. Structural PL dominated lipid dynamics for preflexion larvae, indicating that small individuals allocate the majority of energy toward somatic growth. Conversely, postflexion larvae appear able to switch between growth (contribution of PL) and energy storage (contribution of TAG) strategies. The condition index 
25 ratio TAG:Chol varied from 0.2 to $<2$ with no differences between the two larval stages. Further,

26 FA composition of the TAG and PL fractions suggests that both developmental stages share the

27 same carnivorous diet and that $C$. hamatus relies on a few key prey items.

28 Key-words: Larvae, fatty acids, nutritional condition, diet, Antarctica

29

30

31

32

33

34

35

36

37

0

\section{Introduction}

(1)

In the pelagic ecosystem of the Southern Ocean, icefish (Channichthyidae, 'whiteblooded' fish) form a family within the perciform suborder Notothenioidei, the most predominant suborder of demersal Antarctic fishes (Kock 2005). Early life stages of most species of channichthyids have been described (Efremenko 1987; Kellermann and Schadwinkel 1991) and their distribution and relative abundance reviewed elsewhere (La Mesa and Ashford 2008; Loeb et al. 1993). At hatching, larvae of channichthyids are relatively large (13-17 mm), suggesting greater likelihood of survival compared to smaller larvae of other Antarctic fishes (Kock 2005). In addition, larval channichthyids exhibit relatively fast growth rates and feed primarily on young stages of euphausiids and larval nototheniids (Kellermann 1990; La Mesa et al. 2011). Although most channichthyids are demersal-benthic as adults, larvae and postlarvae are typically pelagic. The most common channichthyid within the pelagic communities of the Ross and Dumont D'Urville Sea are larval and juvenile Chionodraco sp. (Granata et al. 2002; North 1988). The genus Chionodraco includes C. hamatus, C. myersi, and C. rastrospinosus, with C. hamatus and C. myersi previously identified from the Dumont d'Urville Sea (Koubbi et al. 2010). As the taxonomic identification of larval stages of Chionodraco sp. is still unclear (Kellermann 1990), most authors base larval identification on the co-occurrence of adults in the 
47 same area (Hubold 1990; Moteki and Ishimaru 2008). In the Dumont d'Urville Sea, adult $C$.

48 hamatus are overwhelmingly more common than adult C. myersi (Koubbi et al. 2009), and some

49 barcoded larvae have been identified as C. hamatus (Dettai, pers. comm.). Therefore, larvae of 50 the genus Chionodraco are referred to as C. hamatus in this study.

The life history and biology for early life stages of $C$. hamatus remain poorly understood.

52 This species has been reported to spawn during summer in the Ross Sea (La Mesa et al. 2003;

53 Vacchi et al. 1996) and demonstrates nesting behavior (Ferrando et al. 2014). Hatching time is

54 not known, although presumably occurs in summer/autumn because few reproductively active

55 females have been observed in the coastal zone near the Dumont d'Urville station in January

56 (Koubbi, pers. comm.).

57 In polar regions, lipids and their constituent FA play major roles in growth, movement, 58 buoyancy, and reproduction, and also represent the main energy reserves of many polar species 59 (Sargent et al. 2002). Lipid class dynamics reflect the ability of fish larvae to withstand 60 starvation events and can be used to determine a lipid-based condition index (Fraser 1989;

61 Giraldo et al. 2012; Håkanson 1989). The lipid condition index is based on the principal 62 assumption that larval condition in many marine organisms is dependent upon lipid energy 63 reserves, which typically correspond to triacylglycerol (TAG) content. TAG content is dependent 64 on larval size or body mass and must be standardized by cholesterol (Chol) content; Chol is a 65 membrane lipid that is correlated with larval size but is independent of nutritional condition 66 because it is not catabolized during starvation (Fraser 1989).

The relationship between the storage-class lipids (TAG) and the structural membrane 68 lipids (polar lipids, PL) to total lipids (TL) also reflects the main metabolic strategy of larvae and 69 the tradeoff between energy allocation toward growth and/or lipid storage. Further, FA 
composition of the TAG fraction directly reflects FA composition of the diet, and differences in

71 FA composition between different organisms or developmental stages therefore reflect dietary

72 similarities/differences (Dalsgaard et al. 2003). In contrast, FA composition of the PL fraction is

73 under genetic control (i.e. independent of diet) and can be used to determine ontogenetic changes

74 within an organism (Giraldo et al. 2015a).

75 In this study, the lipid composition and dynamics of C. hamatus are analyzed to (1)

76 determine lipid composition and the role of lipids in early life strategies of C. hamatus, and (2)

77 provide an overview of the lipid class-specific FA composition of C. hamatus that can be used to

78 determine trophic pathways in the East-Antarctic pelagic ecosystem.

\section{Materials and Methods}

\section{a. Sampling}

Field sampling was conducted in the Dumont d'Urville Sea (East Antarctica) during the austral summer 2010-2011 as part of the French IPEV-ICO2TA program (Integrated Coastal Ocean Observations in Terre Adélie) (Koubbi et al. 2011). Larval fish samples were collected from the RV “L'Astrolabe” using an Isaacs-Kidd midwater trawl (IKMT) at four stations along transects oriented from nearshore to across the continental shelf located from the Mertz Glacier Tongue to the Adelie Bank. All samples $(n=26)$ were immediately frozen in liquid nitrogen $\left(-196^{\circ} \mathrm{C}\right)$ and stored at $-80^{\circ} \mathrm{C}$ until further analysis. Back to our laboratory, samples were thawed on ice, weighted (degree of precision $0.01 \mathrm{mg}$ ) and measured to the nearest $0.1 \mathrm{~mm}$ with a digital caliper (standard length, SL) before analysis. Two larval developmental stages were differentiated based on flexion and corresponded to specimens smaller (pre-flexion, $n=16$ ) and larger (post-flextion, $n=10$ ) than $25 \mathrm{~mm}$. Preflexion larvae were defined as having a straight notochord with depleted yolk reserves. The second group corresponded to postflexion larvae and was characterized by an 
93 angled notochord with partially developed anal and dorsal fins. These two distinct larval stages

94 were subsequently separated for further lipid analysis.

95

97

\section{b. Lipid analysis}

Lipid extraction followed the method of Bligh and Dyer (1959) as modified by Mayzaud et al. (2007). Samples were mechanically homogenized and twice-extracted with a one-phase solvent mixture of methanol:chloroform:water $(2: 1: 0.8 \mathrm{v} / \mathrm{v} / \mathrm{v})$. Phases were separated overnight by addition of chloroform and $\mathrm{NaCl} 0.7 \%(\mathrm{w} / \mathrm{v})$ to a final solvent ratio of 2:2:1.8 methanol:chloroform:water (v/v/v). The total extract was vacuum concentrated using a rotary evaporator and stored under nitrogen at $-80^{\circ} \mathrm{C}$ in the laboratory.

TL content was determined gravimetrically. Lipid classes were quantified using a chromatographic separation coupled with FID (Flame Photometry Detection) detection on an Iatroscan MK V TH 10. TL extracts were applied to SIII chromarods using a SAS A4100 autospotter programmed to deliver $1 \mu \mathrm{l}$ of chloroform extract per rod. Analyses were performed in triplicate. Lipid classes were separated by chromatography using a double development procedure with the following solvent systems: n-hexane:benzene:formic acid 80:20:1 (v/v/v) followed by n-hexane:diethyl ether:formic acid 97:3:1.5 (v/v/v). The FID was calibrated for each compound class using commercial standards. For FA analysis, lipid classes were isolated by thin layer chromatography with the hexane:diethyl ether:acetic acid 170:30:2.5 (v/v/v), and the band of PL was then scraped off from the origin and eluted. Lipid classes were visualized using dichlorofluorescein and identification was achieved by comparison with standard mixtures. Following identification, the TAG fraction was then scraped off and eluted. FA from PL and TAG were subsequently converted into methyl esters with $7 \%$ boron trifluoride in methanol 
115 (Morrison \& Smith 1964). A control thin layer chromatography was performed to verify the 116 efficiency of the trans methylation procedure.

Gas chromatography (GC) of all FA methyl esters (FAME) was carried out on a $30 \mathrm{~m}$

118 (length) x $0.32 \mathrm{~mm}$ (width) internal diameter quartz capillary column coated with Famewax

119 (Restek) in a Perkin-Elmer XL Autolab GC equipped with FID. The column was operated 120 isothermally at $185^{\circ} \mathrm{C}$ for FAME. Helium was used as carrier gas at 7 psig. Injector and detector 121 were maintained at $250^{\circ} \mathrm{C}$. Individual components were identified by comparing retention time 122 data with those obtained from laboratory standards (capelin:menhaden oils, 50:50). In addition, 123 FAME samples were hydrogenated to confirm FA determination. The level of accuracy was $\pm 3 \%$ 124 for major components, 1-9\% for intermediate components, and up to $\pm 25 \%$ for minor 125 components ( $<0.5 \%$ of total FA). In order to have enough material for GC analysis, two to three 126 preflexion larvae were pooled together according to their TAG:Chol ratio. Postflexion larvae 127 were analyzed individually.

\section{c. Statistics} TL, WW and SL. Contribution of main lipid classes (i.e. Chol, PL and TAG) to TL was assessed using linear regression on standardized values ( $\mu$ g lipid class per mg WW). Correspondence 132 analysis (CA) (Benzécri et al. 1973) has been widely applied to analyze ecological data (Giraldo 133 et al. 2015b) and was chosen here to describe the total inertia in the multi-dimensional FA data 134 as a sample of fewer dimensions that best visualizes patterns in the data. The FA matrix was 135 transformed to relative frequencies and scaled such that each row (or column) can be viewed as a 136 row (or column) of conditional probability distribution. Distances between profiles were 
137 computed with $X^{2}$ metrics. This distance gives symmetry to the 2 sets of data such that each 138 factorial axis of the cloud of variables corresponds to a factorial axis of the cloud of 139 observations. Thus, it was possible to represent both descriptors and observations on the plane 140 defined by the factorial axes. The percent variance explained is given for each analysis. Symbol 141 size is proportional to the cosine ${ }^{2}$, illustrating the quality of representation for each point. 142 Computations were performed in the statistical software package $\mathrm{R}$ ver. 3.1 .0 (R Team Core 143 2012). Data were transformed to normalize (Zar 1999).

\section{Results}

145 Size, weight and lipid components

The SL of $C$. hamatus $(\mathrm{n}=26)$ ranged from 19.3 to $35.1 \mathrm{~mm}$ with $\mathrm{WW}$ from 31 to 249

147

148

149

150

151

152

153

154

155

156 mg. The regression between WW and SL was described by a log-log function (Eq. 1):

(1) $\log (W W)=-2.1+2.9 * \log (S L), \quad F=100.4, d f=24 p<0.001, R^{2}=0.80$

TL content varied from 1.1 to $2.1 \%$ (of WW) and was positive correlated with WW and SL, as described by the following equations (Eq. 2 \& Eq. 3):

(2) $\log (T L)=-2.0+1.1 * \log (W W), F=584.4, d f=24, p<0.001, R^{2}=0.96$

(3) $\log (T L)=-4.3+3.2 * \log (S L), F=76.2, d f=24, p<0.001, R^{2}=0.75$

Chol and PL content were used to indicate the mass of an individual. A relatively good linear fit (Fig. 1) shows that these lipid components are indeed indicative of larval weight (Eq. 4 \& Eq. 5):

(4) $\log (\mathrm{Chol})=-1.70+1.59 * \log (W W), F=69.1, d f=24, p<0.001, R^{2}=0.73$

(5) $\log (L P)=0.36+1.39 * \log (W W), F=205.8, d f=24, p<0.001, R 2=0.89$ 
PL were the major constituent in both larval stages $(96.2 \pm 1.7 \%$ and $94.1 \% \pm 2.5 \%$ for

158

\section{Fatty acid signature}

178

179

\section{Lipid dynamics}

\section{Polar lipids}

pre-flexion and post-flexion, respectively) followed by Chol (1.96 $\pm 0.6 \%$ and $2.70 \pm 1.1 \%)$ and TAG (1.5 $\pm 0.2 \%$ and $3.0 \pm 1.5 \%)$. In some samples free FA and diacylglycerols were identified but represented less than 1\% of TL. Wax esters were not present.

The contribution of the main lipid classes (i.e. PL, Chol and TG) to TL content was analyzed by standardizing lipids ( $\mu \mathrm{g})$ by WW (mg). In preflexion larvae, PL and Chol were the dominant constituent influencing changes in TL (Linear regression $F=24470$ and 30.84, respectively; $d f=14, p<0.001$ ), while TAG levels were low relative to other lipid fractions and did not contribute significantly to TL content (Linear regression, $F=0.55, d f=14, p=0.46$ ) (Fig. 2). Similarly, PL dominated TL in postflexion larvae, but all lipid classes contributed significantly to changes in TL (Linear regression $F=2039,37.15$, 34.6 for PL, Chol and TAG respectively, $d f=8, p<0.001$ ) (Fig. 3).

\section{Condition index TG:Chol}

Although there was a slightly better fit between PL and WW than between Chol and WW, Chol was used to standardize TAG content because PL can be mobilized during starvation and might therefore be less stable. The TAG:Chol ratio varied between 0.18 to 1.74 in preflexion larvae and from 0.22 to 2.20 in postflexion larvae. No significant differences were detected for TAG:Chol ratios (Wilcoxon test, $W=45, p>0.05$ ) between the two larval stages. 
Overall, saturated ( 26\%) and polyunsaturated FA (PUFA, 45\%) dominated the FA

181

182

183

184

185

186

187

188

189

190

191

192

193

194

195

196

197

198

199

200

201

202

composition of the PL fraction of each larval stage (Table 1). For all developmental stages, saturated FAs were dominated by palmitic acid (16:0) and, to a lesser extent, by stearic acid (18:0). Monoenoic acids ( 23\%) were dominated by oleic (18:1n-9), vaccenic (18:1n-7) and palmitoleic (16:1n-7), while PUFA were dominated by EPA (20:5n-3) and DHA (22:6n-3). Correspondence analysis explained $52 \%$ of the variance between the FA of preflexion and postflexion larvae. Individuals were distributed around the centroid of the analysis with no clear differences between the two stages (Fig 4).

Triacylglycerols

Monoenoic ( 28\%) and PUFA ( 36\%) dominated the TAG fraction of both preflexion and postflexion larvae (Table 1). For all developmental stages, saturated FAs were dominated by palmitic acid (16:0), monoenoic acids were dominated by oleic (18:1n-9), palmitoleic (16:1n-7) and vaccenic acid (18:1n-7), and PUFA were dominated by EPA (20:5n-3) and DHA (22:6n-3). Correspondence analysis explained $73.49 \%$ of variance in FA signature of the TAG fraction of preflexion and postflexion larvae. However, all samples fell within the centroid of the analysis, indicating no marked differences in FA composition between the two larval stages.

\section{Discussion}

Larval development in many marine organisms is largely dependent upon energy reserves, which typically correspond with TAG content. Starvation and predation represent major causes of mortality in larval fishes, particularly once yolk reserves are depleted and larvae must switch to deriving energy from exogenous sources (Leggett and Deblois 1994). Predation risk is lower in individuals with larger body size, and fish larvae are therefore confronted with a 
203 tradeoff between allocating energy reserves to optimize growth, reduce predation risk and 204 increase the opportunity to consume larger prey items, versus storing TAG to increase the 205 likelihood of survival during starvation events. In this study, the dominance of polar structural 206 lipids (PL) compared to TAG content in preflexion larvae $(<25 \mathrm{~mm})$ of $C$. hamatus indicates 207 that small individuals primarily allocate energy reserves toward somatic growth. Conversely, the 208 important contribution of both TAG and PL to TL dynamics of older individuals (> $25 \mathrm{~mm}$, 209 postflexion larvae) suggests an ability to allocate energy toward both growth and lipid storage 210 reserves because the benefits of allocating energy toward growth decrease with increase in body 211 size. Overall, the results of this study highlight a marked ontogeny of energy allocation that 212 likely decreases predation risk for small larvae and favors lipid storage in postlarval C. hamatus. 213 Ratios of TAG:Chol suggested no significant differences in condition factor of pre- and 214 postflexion larvae, indicating that both stages were in good condition and that prey availability 215 during the summer 2011 was sufficient to meet the basal requirements of $C$. hamatus individuals 216 from this study.

PL are known to be strongly regulated and appear to be directly related to membrane 218 requirements and specific energetic pathways (reviewed by Sargent et al., 2002 and Dalsgaard et 219 al., 2003). Although the lipid class dynamics of preflexion and postflexion C. hamatus larvae 220 were different, neither of these developmental stages exhibited any detectable ontogeny in the 221 FA pattern of PL and TAG fractions. High levels of DHA with a mean EPA: DHA ratio of $0.6 \pm$ 2220.05 reflects the role of polyunsaturated n-3 FA in the maintenance of biological membranes in 223 C. hamatus larvae. In contrast to PL, the FA composition of TAG is related to trophic 224 interactions in marine organisms (Dalsgaard et al. 2003; Mayzaud et al. 2011). In this study, 225 there were no significant differences between the pattern of FA trophic markers for pre- and 
226 post- larval C. hamatus, indicating similar diet across larval stages. Specifically, early life stages

227 of C. hamatus were characterized by low contribution of Calanus-type copepod markers $228(\Sigma \mathrm{C} 20: 1, \mathrm{C} 22: 1)$ and a relatively high value of the ratio C18:1n-9/C18:1n-7, a typical carnivory 229 index in marine trophic ecology (Hagen et al. 2000). This finding is consistent with previous 230 work demonstrating that young stages of euphausiids (furcilia to juveniles) and fish larvae 231 constitute the most important food source for channichthyids larvae (Kock 2005). Early life stages of the pelagic fish, Pleuragramma antarctica (Antarctic Silverfish), one 233 of the most important key species of Antarctica (along with the krill Euphausia superba) 234 (Corsolini et al. 2002) may be of particular importance in the diet of $C$. hamatus. Early life stages 235 of C. hamatus have been previously reported as specialized predators in the Ross Sea, feeding on 236 a relatively narrow niche width, with $P$. antarctica larvae as their overwhelmingly dominant prey 237 (La Mesa et al. 2011). Compared to the carnivory index previously described for P. antarctica 238 larvae (1.34 and 1.06) (Mayzaud et al. 2011, Tavernier et al. 2012), the relative high value (1.93) 239 of the ratio C18:1n-9/C18:1n-7 reported for C. hamatus is in good agreement with previous 240 studies. Moreover, stable nitrogen signatures $\left(\delta^{15} \mathrm{~N}\right)$, mainly used to establish trophic 241 relationships, have been reported as $10.5 \%$ for $C$. hamatus larvae (SL= 31-38 mm) (Cherel et al. 242 2011) and 6.7 \%o for larval P. antarctica (Giraldo et al. 2011). Considering that, on average, a $243 \sim 3 \%$ enrichment in $\delta^{15} \mathrm{~N}$ values accompanies each trophic step, these results also support the 244 hypothesis that larval $P$. antarctica could be the main prey item for $C$. hamatus larvae. The 245 hatching time of $C$. hamatus and P. antarctica are thought to coincide. Further, C. hamatus and 246 P. antarctica co-occur spatially and have a similar geographic distribution in the western Ross 247 Sea (La Mesa et al. 2010) and offshore of the Antarctic Peninsula (White and North 1987). 248 Future studies could use FA as dietary biomarkers to test the hypothesis that survival of larval $C$. 
hamatus is closely linked to spatial and temporal dynamics of young stages of euphausiids and $P$.

250

251

252

253

254

255

256

257

258

259

260

261

262

263

264

265

266

267

268

269

270

271

272

273

274

275

276

277

278

279

280

281

282

283

284

285

286

287

288

289

antarctica larvae.

\section{Acknowledgements}

This project is a contribution to the Zone Atelier Antarctique du CNRS. Field surveys were funded by the French Polar Institute (IPEV). The authors thank the anonymous reviewers for

their valuable comments to improve the manuscript and Shannon MacPhee from Fisheries and

Oceans Canada for proofreading and editing.

\section{References}

Benzécri JP, Benzécri F, Birou A, Blumenthal S, De Bœck A (1973) L'analyse de données Vol. 2:

L'analyse des correspondances. Dunod, Paris

Bligh EG, Dyer WJ (1959) A rapid method of total lipid extraction and purification. Can J Biochem Phys 37(8):911-917

Cherel Y, Koubbi P, Giraldo C et al (2011) Isotopic niches of fishes in coastal, neritic and oceanic waters off Adélie Land, Antarctica. Polar Sci 5:286-297

Corsolini S, Romeo T, Ademollo N, Greco S, Focardi S (200) POPs in key species of marine Antarctic ecosystem. Microchem J 73(1):187-93

Dalsgaard J, St John M, Kattner G, Müller-Navarra D, Hagen W (2003) Fatty acid trophic markers in the pelagic marine environment. Adv Mar Biol 46:225-340

Efremenko V (1987) Species composition and distribution of mesopelagic fish eggs and larvae in the Ross Sea. Biological and oceanographic investigations of the Pacific sector of Antarctica 186-193

Ferrando S, Castellano L, Gallus L, Ghihliotti L, Masini MA, Pisano E., Vacchi M (2014) A Demonstration of Nesting in Two Antarctic Icefish (Genus Chionodraco) Using a Fin Dimorphism Analysis and Ex Situ Videos. PLoS ONE 9(3): e90512. doi:10.1371/journal.pone.0090512

Fraser AJ (1989) Triacylglycerol Content as a Condition Index for Fish, Bivalve, and Crustacean Larvae. Can J Fish Aquat Sci 46:1868-1873

Giraldo C, Cherel Y, Vallet C, Mayzaud P, Tavernier E, Moteki M, Hosie G, Koubbi P (2011) Ontogenic changes in the feeding ecology of the early life stages of the Antarctic silverfish (Pleuragramma antarcticum) documented by stable isotopes and diet analysis in the Dumont d'Urville Sea (East Antarctica). Polar Sci 5(2):252-63

Giraldo C, Cherel Y, Vallet C et al (2012) Lipid components as a measure of nutritional condition in fish larvae (Pleuragramma antarcticum) in East Antarctica. Marine Biol 160:877-887

Giraldo C, Mayzaud P, Tavernier E, Boutoute M, Penot F, Koubbi P (2015a) Lipid dynamics and trophic patterns in Pleuragramma antarctica life stages. Antarctic Sci 27(5):429-438

Giraldo C, Stasko A, Choy ES, Rosenberg B, Majewski A, Power M, Swanson H, Loseto L, Reist JD (2015b) Trophic variability of Arctic fishes in the Canadian Beaufort Sea: a fatty acids and stable isotopes approach. Polar Biol 1-6. doi:10.1007/s00300-015-1851-4

Granata A, Cubeta A, Guglielmo L, et al (2002) Ichthyoplankton abundance and distribution in the Ross Sea during 1987-1996. Polar Biol 25:187-202

Hagen W, Kattner G, Friedrich C (2002) The lipid compositions of high-Antarctic notothenioid fish species with different life strategies. Polar Biol 23(11):785-91 
Håkanson JL (1989) Analysis of lipid components for determining the condition of anchovy larvae, Engraulis mordax. Marine Biol 102:143-151

Hubold G (1990) Seasonal Patterns of Ichthyoplankton Distribution and Abundance in the Southern Weddell Sea. In: Kerry KR, Hempel G (eds) Antarctic Ecosystems. Springer Berlin Heidelberg, pp 149-158

Kellermann A (1990) Catalogue of early life stages of Antarctic notothenioid fishes. Ber Polarforsch 67:45-136

Kellermann A, Schadwinkel S (1991) Winter aspects of the ichthyoplankton community in Antarctic Peninsula waters. Polar Biol 11:117-127

Kock K-H (2005) Antarctic icefishes (Channichthyidae): a unique family of fishes. A review, Part I Polar Biol 28:862-895

Koubbi P, Duhamel G, Hecq JH et al (2009) Ichthyoplankton in the neritic and coastal zone of Antarctica and Subantarctic islands: A review. J Mar Syst 78:547-556

Koubbi P, Ozouf-Costaz C, Goarant A et al. (2010) Estimating the biodiversity of the East Antarctic shelf and oceanic zone for ecoregionalisation: example of the ichthyofauna of the CEAMARC (Collaborative East Antarctic Marine Census) CAML surveys. Polar Sci 4:115-133

Koubbi P, O'Brien C, Loots C, Giraldo C, Smith M, Tavernier E, Vacchi M, Vallet C, Chevallier J, Moteki M (2011) Spatial distribution and inter-annual variations in the size frequency distribution and abundances of Pleuragramma antarcticum larvae in the Dumont d'Urville Sea from 2004 to 2010. Polar Sci 5(2):225-38

La Mesa M, Ashford J (2008) Age and growth of ocellated icefish, Chionodraco rastrospinosus DeWitt and Hureau, 1979, from the South Shetland Islands. Polar Biol 31:1333-1342

La Mesa M, Caputo V, Rampa R, Vacchi M (2003) Macroscopic and histological analyses of gonads during the spawning season of Chionodraco hamatus (Pisces, Channichthyidae) off Terra Nova Bay, Ross Sea, Southern Ocean. Polar Biol 26:621-628

La Mesa M, Catalano B, Greco S (2011) Larval feeding of Chionodraco hamatus (Pisces, Channichthyidae) in the Ross Sea and its relation to environmental conditions. Polar Biol 34:127137

La Mesa M, Catalano B, Russo A, Greco S, Vacchi M, Azzali M (2010) Influence of environmental conditions on spatial distribution and abundance of early life stages of Antarctic silverfish, Pleuragramma antarcticum (Nototheniidae), in the Ross Sea. Antarct Sci 22:243-254

Leggett WC, Deblois E (1994) Recruitment in marine fishes: Is it regulated by starvation and predation in the egg and larval stages? Neth J Sea Res 32:119-134

Loeb VJ, Kellermann AK, Koubbi P, North AW, White MG (1993) Antarctic larval fish assemblages: a review. B Mar Sci 53:416-449

Mayzaud P, Boutoute M, Perissinotto R, Nichols P (2007) Polar and neutral lipid composition in the pelagic tunicate Pyrosoma atlanticum. Lipids 42(7):647-57

Mayzaud P, Chevallier J, Tavernier E, Moteki M, Koubbi P (2011) Lipid composition of the Antarctic fish Pleuragramma antarcticum. Influence of age class. Polar Sci 5:264-271

Morrison WR, Smith LM (1964) Preparation of fatty acid methyl esters and dimethylacetals from lipids with boron fluoride-methanol. J Lipid Res 5(4):600-8

Moteki M, Ishimaru T (2008) Development of feeding and swimming functions in larvae of Chionodraco rastrospinosus (Channichthyidae). Cybium 32:247-251

Moteki M, Koubbi P, Pruvost P, Tavernier E, Hulley P-A (2011) Spatial distribution of pelagic fish off Adélie and George V Land, East Antarctica in the austral summer 2008. Polar Sci 5:211-224

North A (1988) Distribution of fish larvae at South Georgia: horizontal, vertical, and temporal distribution and early life history relevant to monitoring year-class strength and recruitment SCCAMLR, SeL Sci Pap 4:1987

R Team Core (2012) R: A language and environment for statistical computing

Sargent JR, Tocher DR, Bell JG (2002) The lipids. Fish nutrition 3:181-257 
Tavernier E, Mayzaud P, Boutoute M, Vallet C, Koubbi P (2012) Lipid characterization of Pleuragramma antarcticum (Nothoteniidae) larvae off East Antarctica (139 E-145.10 E) during summer. Polar Biol 35(6):829-40

Vacchi M, Williams R, La Mesa M (1996) Reproduction in three species of fish from the Ross Sea and Mawson Sea. Antarct Sci 8:185-192

Vallet C, Labat J-P, Smith M, Koubbi P (2011) Interannual variations in euphausiid life stage distribution in the Dumont d’Urville Sea from 2004 to 2008. Polar Sci 5:166-178

White MG, North AW (1987) Postlarval Notothenioidei and midwater fish collected during the SIBEX cruise by British Antarctic Survey, 1985. In Proc Congr Europ Ichthyol, Stockholm Vol 1985:405-411)

Zar JH (1999) Biostatistical Analysis (4th Edition) Prentice Hall, Englewood Clifs, New Jersey 
352 Figure 1: Linear regression on log-transformed membrane lipids (Chol: cholesterol, PL: polar lipids, $\mu \mathrm{g})$ 353 and wet weight (WW).

354 Figure 2: Contribution of the main lipid classes (PL: Polar Lipids, TAG: Triacylglycerol, Chol:

355 Cholesterol) to the total lipid (TL) content of preflexion larvae C. hamatus.

356 Figure 3: Contribution of the main lipid classes (PL: Polar Lipids, TAG: Triacylglycerol, Chol:

357 Cholesterol) to the total lipid (TL) content of postflexion larvae of C. hamatus.

358 Figure 4: Correspondence Analysis of the fatty acid signature of the polar lipid fraction for preflexion 359 larvae (L1-6) and postflexion lavae (P1-10) of C. hamatus. 
Table 1: Fatty acid composition of the triacylglycerol and polar lipid fraction in pre-flexion and post-flexion larvae. Minor fatty acids (<1\%) common for all individuals are not shown. Data is reported as means \pm standard deviation.

\begin{tabular}{|c|c|c|c|c|}
\hline \multirow[b]{2}{*}{ Fatty acid/Stage } & \multicolumn{2}{|c|}{ Triacylglycerol } & \multicolumn{2}{|c|}{ Polar Lipids } \\
\hline & Pre - flexion & Post - flexion & Pre - flexion & Post - flexion \\
\hline C14 & $2.49 \pm 0.64$ & $2.60 \pm 0.54$ & $0.96 \pm 0.19$ & $0.97 \pm 0.19$ \\
\hline C15 & $0.47 \pm 0.22$ & $0.30 \pm 0.04$ & $0.18 \pm 0.02$ & $0.18 \pm 0.01$ \\
\hline ISO17 & $0.76 \pm 0.12$ & $0.84 \pm 0.11$ & $0.53 \pm 0.08$ & $0.55 \pm 0.07$ \\
\hline ANT17 & $0.20 \pm 0.06$ & $0.21 \pm 0.06$ & $0.14 \pm 0.05$ & $0.10 \pm 0.05$ \\
\hline C16 & $12.88 \pm 0.77$ & $11.82 \pm 0.37$ & $20.39 \pm 0.49$ & $20.21 \pm 1.37$ \\
\hline C17 & $2.27 \pm 0.36$ & $2.88 \pm 0.23$ & $0.26 \pm 0.03$ & $0.25 \pm 0.04$ \\
\hline C18 & $3.11 \pm 0.34$ & $2.79 \pm 0.22$ & $3.70 \pm 0.25$ & $3.72 \pm 0.29$ \\
\hline$\Sigma$ Saturates & $23.17 \pm 1.27$ & $22.15 \pm 0.86$ & $26.43 \pm 0.43$ & $26.27 \pm 1.62$ \\
\hline C16:1n7 & $7.32 \pm 0.56$ & $7.02 \pm 0.47$ & $3.91 \pm 0.16$ & $3.95 \pm 0.35$ \\
\hline C16:1n5 & $0.81 \pm 0.15$ & $0.85 \pm 0.15$ & $1.03 \pm 0.11$ & $1.00 \pm 0.10$ \\
\hline C18:1n9 & $13.98 \pm 1.28$ & $14.11 \pm 1.29$ & $7.21 \pm 0.24$ & $7.92 \pm 0.71$ \\
\hline C18:1n7 & $7.75 \pm 1.33$ & $7.28 \pm 0.95$ & $8.08 \pm 0.50$ & $7.83 \pm 1.01$ \\
\hline C18:1n5 & $0.95 \pm 0.03$ & $0.97 \pm 0.19$ & $0.75 \pm 0.05$ & $0.79 \pm 0.08$ \\
\hline C20:1n9 & $1.09 \pm 0.24$ & $0.90 \pm 0.32$ & $1.10 \pm 0.11$ & $1.09 \pm 0.11$ \\
\hline C20:1n7 & $0.36 \pm 0.42$ & $0.21 \pm 0.03$ & $0.16 \pm 0.03$ & $0.17 \pm 0.03$ \\
\hline C24:1n9 & $0.23 \pm 0.10$ & $0.20 \pm 0.09$ & $0.16 \pm 0.03$ & $0.21 \pm 0.05$ \\
\hline$\Sigma$ Monoenes & $33.72 \pm 1.78$ & $32.56 \pm 1.61$ & $22.73 \pm 0.28$ & $23.29 \pm 1.57$ \\
\hline C18:2n7 & $0.30 \pm 0.24$ & $0.37 \pm 0.29$ & $0.11 \pm 0.03$ & $0.13 \pm 0.03$ \\
\hline C18:2n6 & $2.28 \pm 0.22$ & $2.42 \pm 0.10$ & $1.15 \pm 0.11$ & $1.34 \pm 0.13$ \\
\hline$\Sigma$ Dienes & $2.79 \pm 0.13$ & $3.06 \pm 0.39$ & $1.51 \pm 0.15$ & $1.76 \pm 0.20$ \\
\hline C16:3n6 & $0.54 \pm 0.17$ & $0.64 \pm 0.11$ & $0.32 \pm 0.06$ & $0.38 \pm 0.07$ \\
\hline C16:3n3 & $0.43 \pm 0.04$ & $0.42 \pm 0.02$ & $0.25 \pm 0.05$ & $0.27 \pm 0.05$ \\
\hline C18:3n6 & $1.41 \pm 0.78$ & $0.57 \pm 0.13$ & $0.17 \pm 0.06$ & $0.14 \pm 0.07$ \\
\hline C18:3n3 & $0.98 \pm 0.37$ & $1.23 \pm 0.13$ & $0.40 \pm 0.13$ & $0.37 \pm 0.14$ \\
\hline$\Sigma$ Trienes & $3.46 \pm 0.76$ & $2.97 \pm 0.26$ & $1.22 \pm 0.22$ & $1.21 \pm 0.21$ \\
\hline C16:4n3 & $0.37 \pm 0.08$ & $0.36 \pm 0.11$ & $0.36 \pm 0.05$ & $0.37 \pm 0.06$ \\
\hline C18:4n3 & $1.93 \pm 0.66$ & $2.77 \pm 0.35$ & $0.49 \pm 0.14$ & $0.58 \pm 0.09$ \\
\hline C20:4n6 & $0.62 \pm 0.11$ & $0.63 \pm 0.09$ & $1.36 \pm 0.14$ & $1.35 \pm 0.10$ \\
\hline$\Sigma$ Tetraene & $3.36 \pm 0.69$ & $4.14 \pm 0.36$ & $2.41 \pm 0.08$ & $2.44 \pm 0.11$ \\
\hline C20:5n3 & $13.6 \pm 0.69$ & $14.85 \pm 0.59$ & $16.77 \pm 0.89$ & $16.26 \pm 1.23$ \\
\hline C22:5n3 & $0.71 \pm 0.06$ & $0.68 \pm 0.08$ & $0.76 \pm 0.07$ & $0.60 \pm 0.04$ \\
\hline C22:6n3 & $18.58 \pm 1.03$ & $19.24 \pm 1.34$ & $28.02 \pm 1.09$ & $28.03 \pm 2.16$ \\
\hline$\Sigma$ PUFA & $33.51 \pm 1.90$ & $35.12 \pm 1.74$ & $45.55 \pm 0.64$ & $44.89 \pm 2.97$ \\
\hline
\end{tabular}



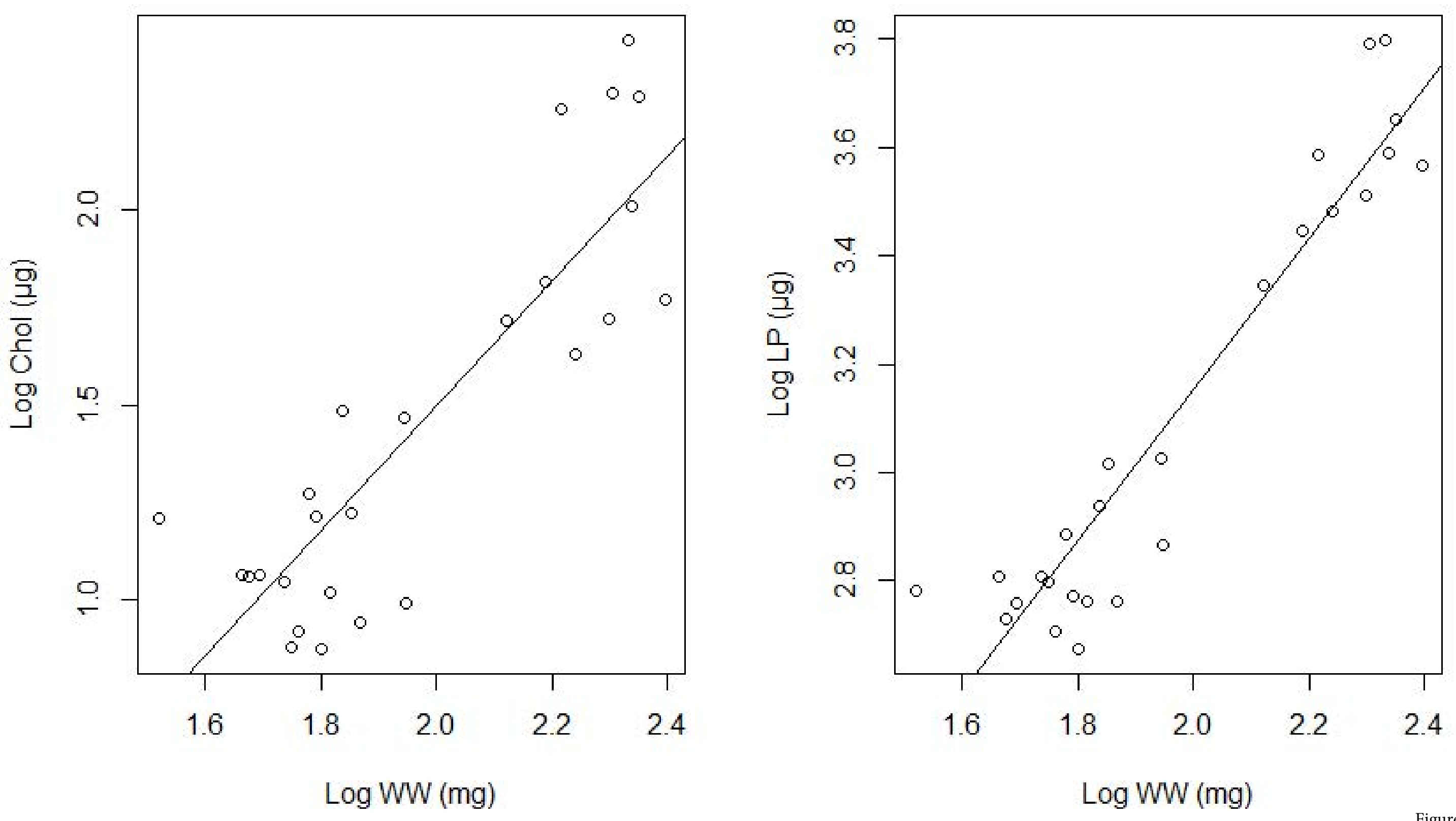
$\Delta \mathrm{PL} \bullet \mathrm{TAG} \square \mathrm{Chol} \longrightarrow \operatorname{Lineal}(\mathrm{PL}) \cdots \cdots$ Lineal $(\mathrm{Chol})$

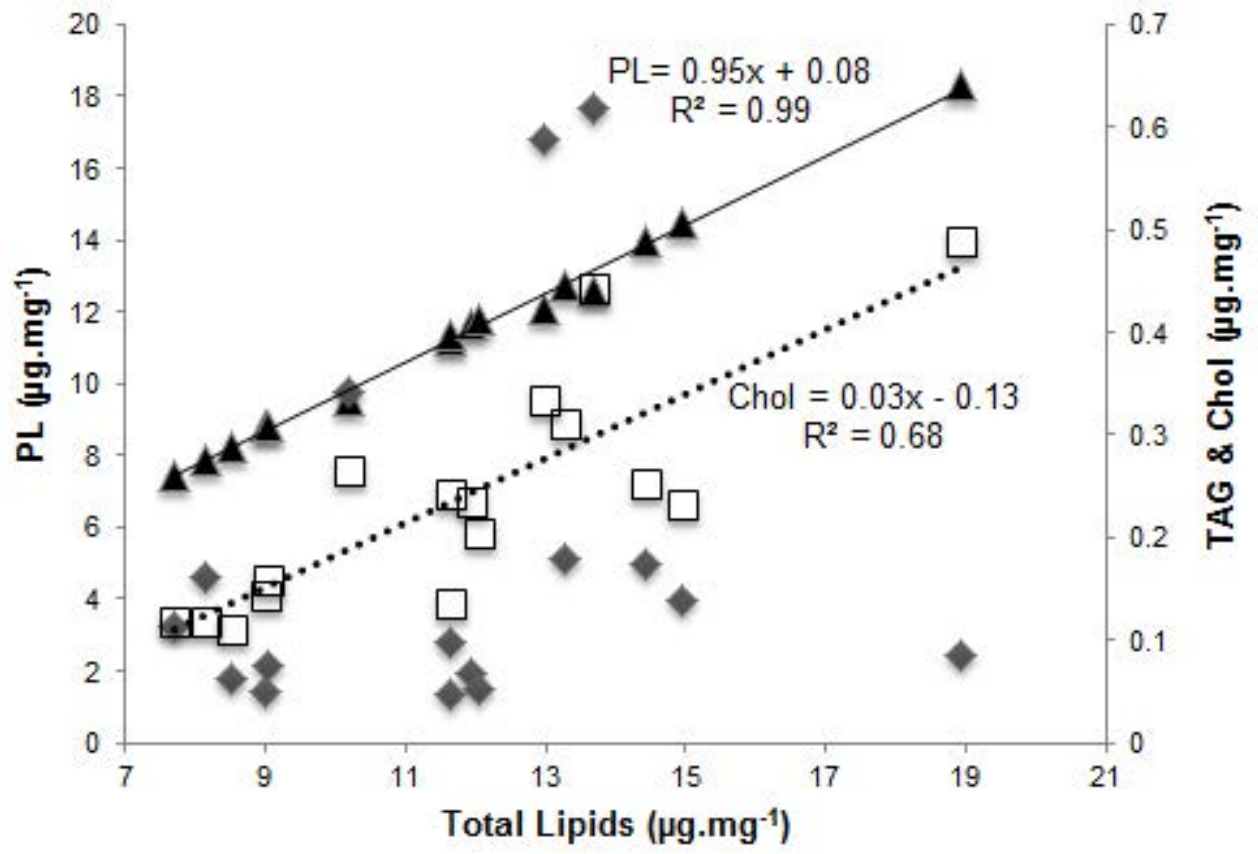

Figure 2 

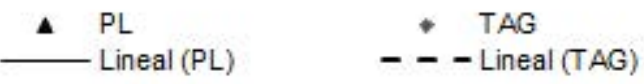

- Chol

...... Lineal (Chol)

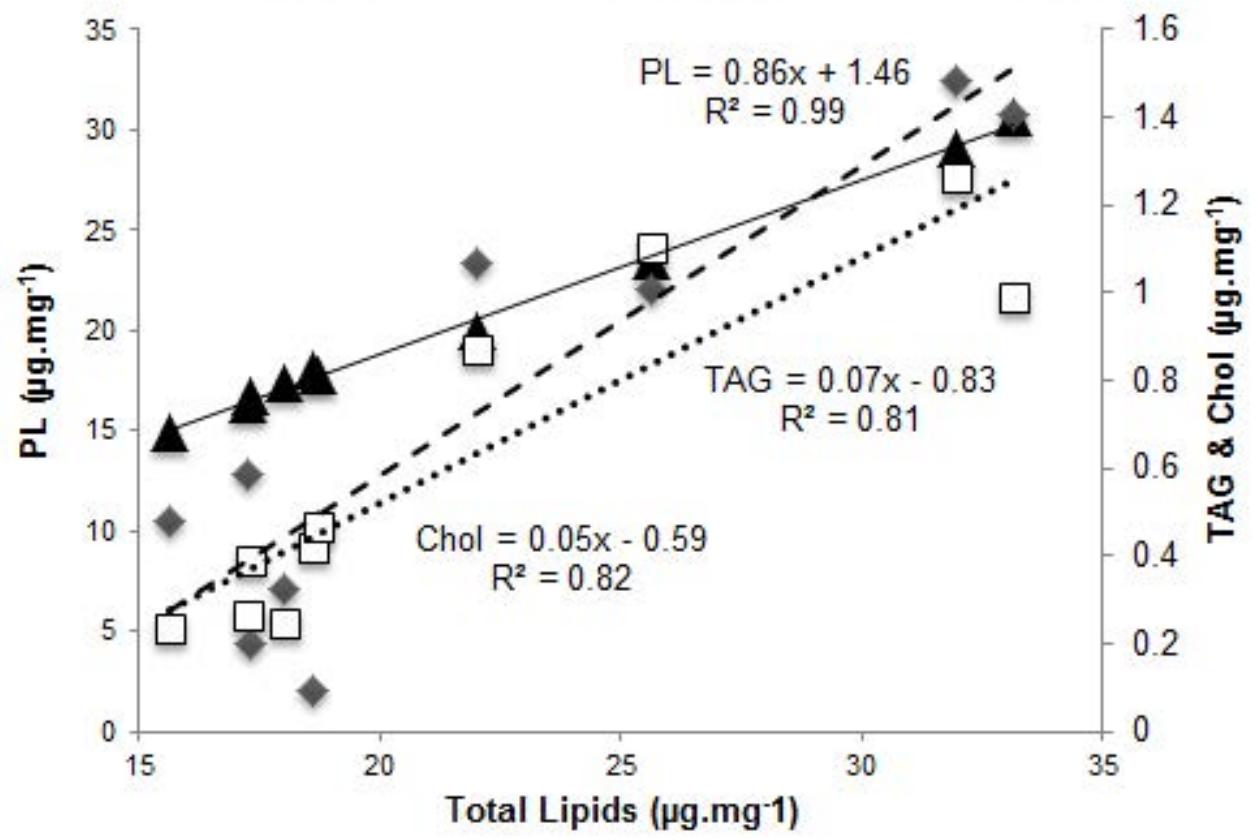

Figure 3 
